\title{
Price Floors and Competition
}

\author{
Martin Dufwenberg, Uri Gneezy, Jacob K. Goeree, and Rosemarie Nagel*
}

June 19, 2002

\begin{abstract}
A potential source of instability of many economic models is that agents have little incentive to stick with the equilibrium. We show experimentally that this may matter with price competition. The control variable is a price floor, which increases the cost of deviating from equilibrium. Theoretically the floor allows competitors to obtain higher profits, as low prices are excluded. However, behaviorally the opposite is observed; with a floor competitors receive lower joint profits. An error model (logit equilibrium) captures some but not all the important features of the data. We provide statistical support for a complementary explanation, which refers to how "threatening" an equilibrium is. We discuss the economic import of these findings, concerning matters like resale price maintenance and auction design.
\end{abstract}

Keywords: Price competition, price floors, Bertrand model, experiment, salience, logit equilibrium, threats

JEL codes: C92, D43, L13

Acknowledgments: We thank Jan Bouckaert, Simon Gächter, Reinhard Selten, Frank Verboven, and the participants at several seminars for stimulating discussions and helpful suggestions. The research has been sponsored by the Swedish Competition Authority. Dufwenberg gratefully acknowledges the hospitality of the Laboratory of Experimental Economics at Bonn University, where he was visiting when the research was completed.

* Dufwenberg: Stockholm University, md@ne.su.se; Gneezy: University of Chicago Graduate School of Business and Technion, uri.gneezy@gsb.uchicago.edu; Goeree: CREED, University of Amsterdam, jkg@fee.uva.nl; Nagel: Pompeu Fabra, rosemarie.nagel@econ.upf.es. 


\section{Introduction}

Students in microeconomics classes are often baffled by the classical prediction that competitive markets with free entry result in zero long-run profits. They wonder why firms would be willing to produce if they gain nothing by doing so. In addition, their own casual observations suggest that profits are non-negligible even in mature markets with close substitutes. Textbooks mostly try to bridge this gap by pointing out that one or more assumptions underlying the zero-profit result may not be met (e.g. by introducing capacity constraints, market power through product differentiation, costly entry, etc.). However, they rarely address the awkwardness of the zero-profit outcome in the standard case. One interpretation of the students' uneasiness with this prediction is in terms of lack of cost of deviating from the equilibrium. Why should firms exhibit rational equilibrium behavior if at the equilibrium they have no incentive to do so?

The Bertrand model of price competition, one of the most important pillars of modern oligopoly theory, predicts an equally stark outcome even with as few as two firms. ${ }^{1}$ When both firms have the same constant marginal costs, their incentives to capture more market will result in cut-throat competition, driving prices down to marginal costs and eliminating all profits. Again the lack of cost of deviating from the equilibrium casts doubt on the predictive power of this result. In equilibrium, a firm's expected profit function is completely flat and any price (greater than or equal to the marginal cost) yields the same expected payoff. Moreover, if there is a slight chance that the rival will price above marginal cost, a firm is better off setting a higher noncompetitive price as well. 
One way to restore a non-negligible cost of deviating from equilibrium is by introducing minimum prices, or price floors, which are regularly employed in a wide spectrum of markets. For example, it is rather common that suppliers impose bounds on the pricing behavior of retailers (see Ippolito, 1991), and governments sometimes introduce minimum prices for certain goods (e.g., a minimum wage), etc. With a price floor, the competing parties still have an incentive to undercut their rival as in the standard Bertrand game, but if prices spiral downwards as a result, the final price level will be above marginal cost yielding some positive profit. Choosing a sufficiently high price floor thus ensures a non-negligible costs of deviating from equilibrium, and improves the drawing power of the Bertrand-Nash solution.

This simple observation has potentially important policy implications. The introduction of a price floor is normally thought of as being anti-competitive, as it eliminates the firms' most aggressive price choices. Stated differently, the presence of a price floor should benefit the firms since it rules out those price levels that could result in the lowest joint profits. This line of reasoning, however, becomes less convincing if one realizes that the incentives for choosing low price levels are small anyhow. Indeed, a price floor can introduce an equilibrium price level that is attractive enough to be selected. Moreover, it is not a priori clear how this level compares to the average price level that ensues without a price floor if firms try to "coordinate" on supra-competitive prices.

In this paper we report experimental evidence on the effects of a price floor. We study a laboratory duopoly market with competition in prices, and compare the outcomes

\footnotetext{
${ }^{1}$ See Tirole (1988, Chapter 5) for a textbook presentation. The model is named after Bertrand (1883).
} 
of two treatments. In the benchmark treatment, two competitors simultaneously choose their prices from a range that includes the zero-profit Bertrand-Nash solution, and the lowest-price firm "wins the market." The floor treatment is identical except that certain low prices are excluded. As noted above, a Nash equilibrium analysis predicts that the introduction of a price floor results in higher profits. Using the results of our experiment we can reject this theoretical conjecture. In fact, we find the opposite result: when price floors are introduced, firms' profits decrease! In the presence of the price floor, competitors play the equilibrium, i.e. they set the lowest possible price. By contrast, without a price floor, competitors are able to "escape" the bad equilibrium and earn profits significantly higher than those with a price floor.

We test whether the logit equilibrium of McKelvey \& Palfrey (1995) can explain this behavioral difference. Their concept has proven successful in explaining experimental data in a variety of settings. ${ }^{2}$ The logit equilibrium is a generalization of the Nash equilibrium, which incorporates decision error and links the likelihood of a deviation from a best response to the cost of such a deviation. This has cutting power in our framework. To deviate from a Nash equilibrium is more costly with than without a price floor, and logit equilibrium predicts that the Nash equilibrium is more stable in the floor case.

However, the theory cannot pick up all the action in the data. The logit equilibrium allows for a free parameter $\mu$, which measures the (cost of error sensitive) propensity to err. We prove that for any $\mu$ the logit equilibrium predicts higher prices with than without the floor. Although the mark-up of pricing relative to the Nash equilibrium 
is lower with than without the price floor, the difference is not strong enough to have an overall anti-competitive effect such as we observe in the experiment. Our results are unusual in that we document a feature of the data that is impossible to reconcile with the logit equilibrium.

Searching for the missing behavioral link, we introduce and test the following conjecture. Could it be that the players conceive of the general level of payoffs at some Nash equilibrium as a "threat," and that the size of this threat serves as a cue which affects their proclivities? We propose a simple model of adaptive play, in which the players' proclivities concern their willingness to increase the degree of competition. We show that the explanation is not rejected by our data.

Experimental research on price competition goes back to Fouraker and Siegel (1963). See Plott $(1982,1989)$ and Holt (1995) for surveys. ${ }^{3}$ These studies typically do not explore the role of price floors. Isaac \& Plott (1981) and Smith \& Williams (1981) introduce price controls (floors and ceilings) in another kind of market institution: double auctions. These are well known for their extraordinarily competitive properties, and some of the price controls considered reduce competition and may be the source of some inefficiency. The Bertrand duopoly institution we consider contrasts starkly in that a competitive outcome is not realized in the benchmark treatment, and in that a price control boosts rather then hinders competition.

\footnotetext{
2 See, for example, McKelvey \& Palfrey (1995), Capra et al. (1999), Guarnaschelli et al. (2000).

${ }^{3}$ Examples of more recent work includes Brown-Kruse, Rassenti, Reynolds \& Smith (1994), Cason (1995), Cason \& Davis (1995), Mason \& Phillips (1997), Dufwenberg \& Gneezy (2000, 2002), and Huck, Normann \& Oechssler (2000).
} 
Our study can furthermore be related to a methodological discussion about the role of stake-size and salience in economic experiments. We shall make connections to the relevant literature later.

In the next section we describe the price competition games that we test. We describe the experimental procedure in Section 3, and report results in Section 4. In Section 5 we discuss how to explain our results theoretically, as well as methodological issues concerning performance pay in experiments. Section 6 concludes.

\section{The games}

In this section we describe the Bertrand games considered in the experiment.

\section{A. The benchmark game}

The textbook version of the Bertrand model admits infinitely many strategies, but for the experimental design we consider a discretized version similar to that used by Dufwenberg \& Gneezy (2000, 2002). Each of two players simultaneously chooses a number from the set $\{0,1, \ldots, 100\}$. The player who chooses the lowest number gets paid a certain amount times the number (s)he chose, and the other player gets 0 . In case of a tie the earnings are split.

The game may be interpreted as a duopoly market with price competition: the players are firms; the chosen numbers are prices; the payoffs are profits. Admittedly, this account of real life price competition is stylized. Yet, the key feature of such interaction is present in the game: a tension between incentives for high prices that lead to high profits and incentives for low prices that undercut the competitor. The simplicity of the game 
furthermore means that it can easily be explained in words to subjects without the use of complicated "profit tables".

The zero-profit Bertrand outcome corresponds to the Nash equilibrium $(0,0)$. Due to the discretization, there are two additional Nash equilibria: $(1,1)$ and $(2,2)$. However, in terms of economic intuition these equilibria are much the same: both players make close to zero profit relative to what is available in the game in principle, and there is little incentive not to deviate. We regard all these equilibria as in line with the Bertrand solution. 4

\section{B. The price floor game}

This game is identical to the benchmark game described in section 2.A, except the choices $0,1, \ldots, 9$ are not allowed. In terms of the corresponding economic interpretation, there is a price floor at 10. The solution is for each competitor to bid 10.

\section{The procedure}

The experiment was conducted at the Technion. Students were recruited using posters on campus. The experiment consisted of two treatments with five sessions per treatment (see Appendix B for data tables). The number of bidders was 12 in all sessions and an extra student assisted us. That is, in total, 120 students participated. Each session operated for 10 periods. In each period six pairs of participants were grouped together

\footnotetext{
4 The game theoretic underpinning is most secure for the $(1,1)$ equilibrium, which is supported by a variety of differently motivated solution concepts: $(1,1)$ is the game's only strict equilibrium; 1 is the only evolutionarily stable strategy and the only survivor of iterated elimination of weakly dominated strategies; $\{1\}$ is the game's only fully permissible set (as defined by Asheim \& Dufwenberg, 2002).
} 
according to a random matching scheme, and then (depending on treatment) each pair played one of the games described in Section 2.

In each session, after all 13 students entered the experimental room, they received a standard-type introduction, and were told that they would be paid NIS 20 for showing up (about $\$ 5$ at the time of the experiment). Then, they took an envelope at random from a box, which contained 13 envelopes. 12 of the envelopes contained numbers $(\mathrm{A} 1, . ., \mathrm{A} 12)$. These numbers were called "registration numbers". We asked the participants not to show their registration number to the other students. One envelope was labeled "Monitor", and determined who was the person who assisted us and checked that we did not cheat. That person was paid the average of all other subjects participating in that session.

Each participant then received the instructions for the experiment (see Appendix C), and ten coupons numbered $1,2, \ldots, 10$. After reading the instructions and asking questions (privately), each participant was asked to fill out the first coupon with her registration number and bid for period 1 . In the benchmark treatment the bids had to be integers from 0 to 100 . The only difference between the benchmark treatment and the floor treatment was that in the latter bids had to be integers from 10 to 100 . Participants were asked to fold the coupon, and put it in a box carried by the assistant. The assistant randomly took two coupons out of the box and gave them to the experimenter. The experimenter announced the registration number on each of the two coupons and the respective bids. If one bid was larger than the other, the experimenter announced that the low bid won as many New Israeli Shekel (NIS) as the number she bid, and the other bidder won NIS 0 . If the bids were equal the experimenter announced a tie, and said that 
each bidder won half as many NIS as the number bid. The assistant wrote this on a blackboard such that all the participants could see it for the rest of the experiment. Then the assistant took out another two coupons randomly, the experimenter announced their content, and the assistant wrote it on the blackboard. The same procedure was carried out for all the 12 coupons. Then the subsequent periods were conducted the same way. After period 10 payoffs were summed up, and participants were paid privately.

\section{The results}

From the viewpoint of traditional economic theory, the presence of a price floor should raise the level of prices. Recall that Nash equilibrium pricing is at the level of 0,1 , or 2 in the benchmark treatment and equal to 10 in the price floor game. This theory thus predicts that price floors lead to less competitive pricing.

However, looking at the data one sees clearly that the results point in the opposite direction. Figure 1 shows the mean prices across all session over time. In all periods, mean prices are higher in the benchmark treatment than in the price floor treatment! Moreover, the gap between the prices in the two treatments seems to widen over time.

[Insert figure 1 about here (now in Appendix D)]

A closer scrutiny using statistical tests confirms this picture: In the early periods the difference between mean prices in the two treatments is not significant on any conventional level, using any non-parametric test. However, in later periods, prices are significantly higher in the benchmark treatment than in the floor treatment. For example, 
in period 10 mean prices in the benchmark treatment are significantly higher $(p<0.01)$ using robust-rank order test, one-sided, based on the single sessions (see Siegel and \& Castellan, 1988, pp. 137-144 for the properties of this test).

Statistical tests also suggest that the tendency for prices to change over time is different in the two treatments. In the price floors treatment prices decrease significantly in all five sessions $(r=0.73$ and $p<0.025$, using Spearman-Rank correlation test). By contrast, in the benchmark treatment, mean prices decrease significantly only in two out of five sessions.

The finding that price floors stimulate competition becomes even more stark if one focuses on the occurrence of prices that are lower than or equal to 10 . In the benchmark treatment there are very few (9\%) price choices in this range (and none of those are equilibrium choices of 0,1 , or 2). By contrast, in the price floors treatment, where price choices of 0 up to 9 are not possible, $40 \%$ of the choices are at the specific price of 10. In the final five periods, a whopping $61 \%$ of the choices in this treatment are at the specific price of 10 , while only $13 \%$ are at or below 10 in the benchmark treatment. Figure 2 gives the relative frequencies of prices in intervals of $0-10,11-20,21-30, \ldots, 91-$ 100 , for the final five periods.

[Insert figure 2 about here (now in Appendix D)]

We summarize our main result as follows:

The presence of a price floor may boost competition! 


\section{Discussion}

In this section we explore whether McKelvey \& Palfrey's (1995) concept of logit equilibrium can shed light on our finding, and we present and test a conjecture concerning how behavior may be explained in part by the avoidance of "threats". We also discuss methodological issues concerning "payoff salience" in experimental research.

\section{A. Logit equilibrium}

The Bertrand-Nash equilibrium predicts well in the floor treatment where the cost of deviating from equilibrium is non-negligible, but not in the benchmark treatment, which suggests the importance of "decision errors." In a decision-error model, players make mistakes and the probability of a mistake is inversely related to its cost. In simple decision-making tasks, errors simply add some "noise" around the optimal choice but in interactive contexts such as games they can have a compounding effect. In the Bertrand duopoly pricing game, for example, an upward error by one player makes higher prices by others more profitable, and hence more likely, which reinforces the original error. This way, endogenous errors can cause decisions to be systematically different from Nash predictions. ${ }^{5}$

McKelvey \& Palfrey (1995) develop game theoretic solution concepts that formally capture this. Players' beliefs about others' noisy choices are required to be correct on average, i.e. players' belief distributions match their opponents' choice distributions. A

\footnotetext{
5 For a particularly striking example see Capra et al. (1999) who consider a "traveler's dilemma" game for which logit predictions (and observed choices) are as far away from Nash predictions as possible.
} 
convenient specification is the logit equilibrium, which has proven successful in explaining observed behavior in many different situations. ${ }^{6}$ We examine the theoretical predictions of that concept in a class of Bertrand games of the textbook continuous strategy type, except they admit price floors. We compare the theoretical predictions to our observations.

Let $\pi_{\mathrm{i}}^{\mathrm{e}}(p)$ denote the expected payoff from choosing a price $p$, which depends on the distribution of the rival's price, denoted by $F_{j}(p)$ :

(1) $\quad \pi_{\mathrm{i}}^{\mathrm{e}}(p)=p\left(1-F_{j}(p)\right), \quad i, j=1,2, \quad i \neq j$.

In a decision-error model, choice frequencies are positively (although not perfectly) related to expected payoffs. We denote the choice density by $f_{i}(p)$ with support $\left[p_{L}, 100\right]$ where $p_{L}$ is the price floor (so $p_{L}=0$ or $p_{L}=10$ ). Using the logit specification the choice density is proportional to an exponential of expected payoffs:

(2) $\quad f_{i}(p)=\frac{\exp \left(\pi_{i}^{e}(p) / \mu\right)}{\int_{P_{L}}^{100} \exp \left(\pi_{i}^{e}(y) / \mu\right) d y}, \quad i=1,2$.

The dominator is a constant independent of $p$ that ensures that the density integrates to 1 , and $\mu$ is an "error parameter" that determines how sensitive choices are with respect to differences in expected profits. With $\mu$ very large, payoff differences are irrelevant and behavior is completely random. At the other extreme, as $\mu$ tends to zero,

\footnotetext{
${ }^{6}$ See, for example, McKelvey \& Palfrey (1995), Capra et al. (1999), Guarnaschelli et al. (2000).
} 
the decision rule in (2) limits to the perfect-maximization rule; the best option is chosen with probability one. Note that (2) is not an explicit solution since the densities $f_{i}(p)$ on the left side also appear on the right side (through the expected payoff function that appears in the exponential terms). By differentiating both sides of (2) with respect to $p$, one obtains the differential equation: $\mu f_{i}^{\prime}(p)=\pi_{i}^{\mathrm{e}}{ }_{i}^{\prime}(p) f_{i}(p)$ for $i=1$,2. Taking the derivative of the expected payoff in (1) and substituting the result, we obtain a differential equation for the equilibrium choice density:

$$
\mu f_{i}^{\prime}(p)=\left(1-F_{j}(p)-p f_{j}(p)\right) f_{i}(p), \quad i, j=1,2, \quad i \neq j .
$$

Existence of a solution to (3) follows from Theorem 1 in Anderson, Goeree \& Holt (2001), who consider a general class of games that incorporates the Bertrand pricing game. They also show that the solution to (3) is unique and symmetric across players.

Proposition 1. The logit equilibrium is unique and symmetric across players.

The logit equilibrium can yield predictions that are qualitatively similar to the distribution of observed choices in our experiment.

\section{[Insert figure 3 about here (now in Appendix D)]}

Figure 3 illustrates, giving the equilibrium densities for both treatments with a common value of the error parameter $\mu=1.5$. In the floor treatment the logit equilibrium predicts 
that a substantial number of choices are equal to the floor price and that the density decays rapidly for higher prices. In contrast, in the baseline treatment the logit equilibrium density is much more spread out with almost no choices at the equilibrium price. Hence, in both treatments the logit equilibrium predicts the main features of the histograms of observed choices (compare Figures 2 and 3).

However, the logit equilibrium fails to predict an important aspect of the experimental data: prices in the benchmark treatment are higher than in the floor treatment. It turns out to be impossible to reconcile this finding with the logit equilibrium, as the following theorem shows (see Appendix A for a proof). ${ }^{7}$

PROPOSITION 2. In the logit equilibrium, an increase in the price floor results in higher equilibrium prices in the sense of first-degree stochastic dominance.

The intuition is that, while a higher price floor makes the Nash equilibrium more salient, the deletion of low prices raises the average logit equilibrium price. The discrepancy between this theorem and our main experimental result shows that the logit equilibrium model does not capture all aspects of the data. In the next section we consider a different, more cognitive, explanation for our "anomalous" finding.

\section{B. Threats}

\footnotetext{
7 The proposition compares equilibrium distributions in the two treatments for a given $\mu$. One could rationalize behavior allowing for different values of $\mu$ in the two treatments, but that would give up the basic idea that $\mu$ represents a general (cost dependent but game independent) propensity to make mistakes.
} 
In light of the findings of the previous section, we venture a conjecture on a behavioral regularity that might help explain our experimental findings. Could it be that the players conceive of the general level of payoffs at some Nash equilibrium as a "threat", and that the size of this threat affects the behavioral inclination by which they play the game? This conjecture (which was suggested to us by Reinhard Selten) would suggest that subjects have an inclination to shy away from equilibria which leave them with low payoffs. Applied to our experiment, in the benchmark treatment the equilibrium payoffs are low and the threat severe. The players therefore avoid entering a competitive mode. By contrast, in the price floors treatment, the equilibrium payoffs are higher, the threat less severe, and the players see no strong long-run reason to avoid initiating price wars.

We propose a simple adaptive model which allows for a test whether this pattern of behavior is consistent with our data. Let $p_{\mathrm{t}}$ denote a player's price choice in round $t \in\{1,2, \ldots, 10\}$, let $a_{\mathrm{t}}$ denote the average chosen price among all twelve participants in round $t$, and let $L \in\{0,10\}$ denote the level of the price floor. For any $t \in\{2,3, \ldots, 10\}$, assume that $p_{\mathrm{t}}$ is chosen according to the following (Markovian) rule:

$$
p_{\mathrm{t}} \in \operatorname{argmin}_{x \in\{L, \ldots, 100\}}\left|x-\left[L+\delta\left(a_{\mathrm{t}-1}-L\right)+\varepsilon_{\mathrm{t}}\right]\right|
$$

where $\delta$ is a non-negative constant and $\varepsilon_{\mathrm{t}}$ is a stochastic variable. That is, from round 2 on, each player makes the bid closest to $L+\delta \cdot\left(a_{\mathrm{t}-1}-L\right)$ plus some random error.

The conjecture about threats can be interpreted in the light of this model. Assume that the behavior in round 1 is identical to that which is observed in the experiment. If 
players avoid entering a competitive mode, this means that $\delta=1$. They adjust to the average bid level of the previous period, up to a stochastic component. If players see no strong long-run reason to avoid initiating price wars, this means that $\delta<1$. Thus, give or take the stochastic component, they decrease their bids relative to the average bid of the previous period. The conjecture is that $\delta=1$ in the benchmark treatment, and that $\delta<1$ in the price floors treatment, in line with the idea that the subjects attitude towards increased competition will differ depending on the threat.

The conjecture can be formally tested. We first find maximum likelihood estimates of the parameters $\delta$ and the variance, $\sigma$, of the error term, for each of the two treatments. The estimates are $\delta=0.96(0.08)$ and $\sigma=54(6)$ in the benchmark treatment, and $\delta=0.72(0.14)$ and $\sigma=43(5)$ in the floor treatment. We then test the hypothesis that the true value of $\delta$ equals 1 , against the alternative that it is less than 1 . This hypothesis is not rejected at conventional levels in the benchmark treatment $(p=0.31)$. It is rejected in the floor treatment $(p=0.04)$, in favor of the hypothesis that $\delta<1$. We interpreted this as support for the threat conjecture.

\section{Salience}

Our study can be related to a methodological discussion concerning stake-size in experiments. In a classic article, Vernon Smith (1982) lists several desiderata of an economic experiment. Among them is salience, summarized by Davis \& Holt (1993, p. 24) as requiring "that changes in decisions have a prominent effect of rewards". It may seem desirable to have salient payoffs in experiments, and some controversies in experimental economics have evolved around these issues (see, e.g., Harrison (1989) and 
the subsequent exchange in the September 1992 issue of the American Economic Review).

There is evidence that the salience of payoffs may be important in experiments. For example, Smith \& Walker (1993) show that when you pay subjects more the variance around the equilibrium is smaller, and Capra et al. (1999) show that increasing salience of best responding while preserving a Nash equilibrium may improve the performance of that equilibrium. Our results, too, suggest that the issue of salience is important. Lack of salience of payoffs around the equilibrium can explain why the Bertrand model fails (and the logit equilibrium can diagnose this).

One must not misinterpret this result. It does not suggest that experimental tests of the Bertrand model are inherently problematic, or that an experimental design is flawed when the Bertrand model fails. Non-salience of equilibrium payoffs follows from the very nature of a Bertrand game, and if real markets resemble Bertrand games non-salience of payoffs will be a feature to reckon with.

\section{Concluding remarks}

From the viewpoint of traditional theory, the introduction of price floors in Bertrand models protect competitors from making low or zero profits, and should thus be anti-competitive. With our experiment we have shown that the opposite can be true: the presence of a price floor fostered competition and lead to more competitive pricing!

This finding has potentially important consequences for how to understand economic situations where there is competition in prices. Consider, for example, the practice of suppliers to impose bounds on the pricing behavior of their retailers. Although 
this practice, which is often called "resale price maintenance," may be illegal, it is very common. ${ }^{8}$ Its occurrence has been viewed as a puzzle by economists and has inspired many theoretical attempts at explanation. ${ }^{9}$ These explanations, however, do not exploit the possible lack of drawing power of a Bertrand equilibrium. Could it be that suppliers practice resale price maintenance because they wish prices to be low when customers shop (the low profits hurting the retailers rather than the suppliers), so that the customers buy more?

Another example for which our results may be important concerns auction design. First-price auctions are structurally very similar to Bertrand games. Consider, for instance, the case of a procurement auction, where a government agency invites bids from competing firms to determine which firms should get the right to some "project". These bids are "prices" that the firms quote, and whoever sets the lowest price wins the project. The insight that price floors can foster competition translates to the insight that the introduction of a minimum bid might make the competing firms more aggressive in a procurement auction.

Yet another example might concern the impact of minimum wage legislation. Suppose two workers compete for the same job, making offers regarding the wage for which they are willing to take employment. The structure of this situation resembles that of our experimental games. Minimum wage legislation would correspond to a price floor, and our result would suggest that such legislation might lead to lower wages. ${ }^{10}$

On a more general level, our results highlight a possible weakness of economic models in which the equilibria provide little incentives for decision makers to stick with the equilibrium. Bertrand competition is just one example. Of course, this point should

\footnotetext{
${ }^{8}$ See Ippolito (1990) for a wealth of empirical evidence.

${ }^{9}$ See Chen (1999) for a recent model and further references.
} 
not be oversold, as in fact earlier Bertrand experiments show by documenting features (other than price floors) that induce fierce competition. ${ }^{11}$ Nevertheless, we believe that we have isolated an "effect" which deserves to be taken seriously.

When the concern is important, economic theorists should beware and attempt to provide new models which can explain behavior and give better predictions. We have made some attempts along such lines, for the specific experimental context we considered. We tried to explain the data using McKelvey \& Palfrey's (1995) logit equilibrium model, which seemed apt since it can capture how different costs of deviating from an equilibrium influences the drawing power of that equilibrium. That model does fine in terms of predicting that the equilibrium of the benchmark game is unstable, and that the equilibrium in the price floor game works fine. However, the concept fails to capture quantitatively what happens in the benchmark treatment. The logit equilibrium cannot explain why in the benchmark treatment prices are higher than in the price floor treatment.

Our interpretation, supported by our estimations of a simple model of adaptive play, refers to the size of the equilibrium payoffs. With a price floor, the threat of arriving at the equilibrium is not that daunting, so the players are prone to compete vigorously. Once at the equilibrium, the costs of deviating are non-negligible, so the players stick. Without a price floor, by contrast, the equilibrium payoffs are low and threatening, so the players avoid increasing the level of competition.

\footnotetext{
10 It is noteworthy that a similar conclusion has been derived in some search theoretical work, although the mechanisms at work seem completely unrelated. See Fershtman \& Fishman (1994).

11 For example, the Bertrand model tends to work rather well if a sufficiently large number of competitors interact, and the information conditions in the market may matter subtly. Dufwenberg \& Gneezy (2000, 2002) report results about this using games which are similar to our benchmark game.
} 
To develop a general model of "threat avoidance" (possibly coupled with those costs of error-related effects that the logit concept is capable of picking up), which can be applied to any game, is a task beyond the scope of our paper. In the light of what we have found in this study, it would seem that such a model must make assumptions about the cognitive steps by which decision makers choose how to behave. In our context, anticipation of a possible equilibrium, and some assessment of the desirability of that outcome, seems to feed back on the players proclivities towards competition. One can imagine that in other games other details related to the structure of the game affect other proclivities, say the tendencies to cooperate, to lie, or to take revenge. A general theory about all of this must be a task for the future. It seems reasonable to expect that it should be developed hand-in-hand with careful experimentation.

\section{References}

Asheim, G.B. \& M. Dufwenberg (2001), "Admissibility and common belief", forthcoming in Games and Economic Behavior.

Bertrand, J. (1883), Review of Theorie Mathematique de la Richesse Sociale and Recherches sur les Principes Mathematique de la Theorie des Richesse, Journal des Savants, 499-508.

Brown-Kruse, J., S. Rassenti, S. Reynolds \& V. Smith (1994), "Bertrand-Edgeworth Competition in Experimental Markets", Econometrica 62, 343-71.

Capra, M, J.Goeree, C. Holt, and R. Gomez (1999), "Anomalous Behavior in a Traveler's Dilemma?" American Economic Review, June 1999.

Cason, T. (1995) "Cheap Talk Price Signaling in Laboratory Markets", Information Economics and Policy 7, 183-204.

Cason, T. \& D. Davis (1995), "Price Communications in a Multi-Market Context: An Experimental Investigation", Review of Industrial Organization 10, 769-87. 
Chen, Y., "Oligopoly Price Discrimination and Resale Price Maintenance", RAND Journal of Economics 30, 441-455.

Dufwenberg, M. \& U. Gneezy (2000), "Price Competition and Market Concentration: An Experimental Study", International Journal of Industrial Organization 18, 7-22.

Dufwenberg, M. \& U. Gneezy (2002), "Information Disclosure in Auctions: An Experiment, Journal of Economic Behavior and Organization 48, 431-44.

Fershtman, C. \& A. Fishman (1994), "The 'Perverse' Effect of Wage and Price Controls in Search Markets" European Economic Review 38, 1099-1112.

Fouraker, L. \& S. Siegel (1963), Bargaining Behavior, New York, McGraw-Hill.

Guarnaschelli et al. (2000), "An Experimental Study of Jury Decision Making," American Political Science Review, 407-424.

Harrison, G. (1989), "Theory and Misbehavior of First-Price Auctions", American Economic Review 79, 649-62.

Holt, C. (1995), "Industrial Organization: A Survey of Laboratory Research", in Handbook of Experimental Economics, eds. J. Kagel and A. Roth, Princeton Univ. Press.

Huck, S., H.-Th. Normann \& J. Oechssler (2000), "Does Information about Competitors Actions' Increase or Decrease Competition in Experimental Oligopoly Markets?", International Journal of Industrial Organization 18, 39-57.

Ippolito, P.M., "Resale Price Maintenance: Empirical Evidence from Litigation", Journal of Law and Economics 34, 263-294.

Isaac, M. \& C. Plott (1981), "Price Controls and the Behavior of Auction Markets: An Experimental Study", American Economic Review 71, 448-59.

McKelvey, R. \& T. Palfrey (1995) "Quantal Response Equilibria for Normal Form Games," Games and Economic Behavior 10, 6-38.

Mason, C. \& O. Phillips (1997), "Information and Cost Asymmetry in Experimental Duopoly Markets", Review of Economics and Statistics, May issue, 290-99.

Plott, C. (1982), "Industrial Organization and Experimental Economics", Journal of Economic Literature 20, 1485-1587.

Plott, C. (1989), "An Updated Review of Industrial Organization: Applications of Experimental Economics," in Handbook of Industrial Organization, vol II, R. Schmalensee \& R. Willig (eds.), Amsterdam: North Holland. 
Siegel, S. \& J. Castellan (1988), Nonparametric Statistics for the Behavioral Sciences, McGraw-Hill.

Smith, V. (1982), "Microeconomic Systems as an Experimental Science", American Economic Review 72, 923-55.

Smith, V. \& J. Walker (1993), "Money Rewards and Decision Costs in Experimental Economics," Economic Inquiry, 245-61.

Smith, V. \& A. Williams (1981), "On Non-Binding Price Controls in a Competitive Market ", American Economic Review 71, 467-74.

Tirole, J., The Theory of Industrial Organization, MIT Press: Cambridge, Mass., 1994. 


\section{Appendix A: Proof of Proposition 2}

PROPOSITION 2. In the logit equilibrium, an increase in the price floor results in higher equilibrium prices in the sense of first-degree stochastic dominance.

Proof. Suppose $p_{L}^{\mathrm{I}}<p_{L}^{\mathrm{II}}$, and let the corresponding symmetric equilibrium distributions be denoted by $F_{\mathrm{I}}(p)$ and $F_{\mathrm{II}}(p)$. We have to show that $F_{\mathrm{I}}(p)$ produces stochastically lower prices, i.e. $F_{\mathrm{I}}(p)>F_{\mathrm{II}}(p)$ for all interior $p$. Suppose, in contradiction, that $F_{\mathrm{I}}(p)$ is lower for some interior price $p^{*}$. Since $p_{L}^{\mathrm{I}}<p^{\mathrm{II}}, F_{\mathrm{II}}$ starts out below $F_{\mathrm{I}}$ and there must be a price $q<p^{*}$ where the distributions first cross, $F_{\mathrm{I}}(q)=F_{\mathrm{II}}(q)$, with $F_{\mathrm{II}}$ approaching from below so $f_{\mathrm{I}}(q) \leq f_{\mathrm{II}}(q)$. The logit density in (2) can be written as $f(p)=K \exp (p(1-F(p)) / \mu)$ where the constant $K=f(100)$ since $F(100)=1$. Hence $f_{\mathrm{I}}(q) \leq f_{\mathrm{II}}(q)$ and $F_{\mathrm{I}}(q)=F_{\mathrm{II}}(q)$ translate into $f_{\mathrm{I}}(100) \leq f_{\mathrm{II}}(100)$. The distributions necessarily cross again (both are 1 at the upper end 100) now with $F_{\mathrm{I}}$ coming from below, which implies $f_{\mathrm{I}}(100) \geq f_{\mathrm{II}}(100)$. So it must be the case that $f_{\mathrm{I}}(100)=f_{\mathrm{II}}(100)$ and dividing the two densities yields $f_{\mathrm{I}}(p) / f_{\mathrm{II}}(p)=$ $\exp \left(p\left(F_{\mathrm{II}}(p)-F_{\mathrm{I}}(p)\right) / \mu\right)$. Now consider the price $q$ where the distributions first cross and let $q^{\prime}$ (possibly 100) denote the next crossing. For all prices $p$ between $q$ and $q$ we have $F_{\mathrm{I}}(p)<F_{\mathrm{II}}(p)$ so $f_{\mathrm{I}}(p) / f_{\mathrm{II}}(p)=\exp \left(p\left(F_{\mathrm{II}}(p)-F_{\mathrm{I}}(p)\right) / \mu\right)>1$. Hence $f_{\mathrm{I}}(p)>f_{\mathrm{II}}(p)$ for all $p$ between $q$ and $q^{\prime}$, which contradicts the equality of the distributions at $q$ and $q^{\prime}$. Q.E.D. 


\section{Appendix B: Data}

\section{Table 1/0}

\begin{tabular}{|c|c|c|c|c|c|c|c|c|c|c|c|}
\hline \multicolumn{12}{|c|}{ Stage \# } \\
\hline \multirow{15}{*}{$\begin{array}{l}\mathrm{P} \\
\mathrm{L} \\
\mathrm{A} \\
\mathrm{Y} \\
\mathrm{E} \\
\mathrm{R}\end{array}$} & & 1 & 2 & 3 & 4 & 5 & 6 & 7 & 8 & 9 & 10 \\
\hline & P1 & $21 *$ & 23 & 30 & 23 & $19 * *$ & $18 * *$ & $20^{*}$ & $17 *$ & $16^{*}$ & $29 *$ \\
\hline & $\mathrm{P} 2$ & $28 *$ & $32 * *$ & $25^{*}$ & $22 *$ & 19 ** & $20 *$ & 17 & 30 & $35^{*}$ & 35 \\
\hline & P3 & 100 & $30 *$ & $20 *$ & $25^{*}$ & $20^{*}$ & $20 *$ & 17 & $30 *$ & 35 & 40 \\
\hline & $\mathrm{P} 4$ & 50 & 40 & 35 & 35 & 99 & 32 & 70 & 50 & 39 & 44 \\
\hline & P5 & 60 & 60 & 36 & 36 & 26 & 30 & 50 & 60 & 66 & 100 \\
\hline & P6 & 45 & $25^{*}$ & 29 & 30 & 25 & 23 & $15^{*}$ & 43 & 45 & 30 \\
\hline & P7 & $13 *$ & $21 *$ & 23 & 23 & $19 *$ & 18 ** & $16^{*}$ & 15 & $10 *$ & $23 *$ \\
\hline & P8 & $37 *$ & $32 * *$ & $31 *$ & 26 & $18 *$ & $16^{*}$ & $13^{*}$ & $11 *$ & $10 *$ & $19^{*}$ \\
\hline & P9 & $10^{*}$ & 49 & $29 *$ & $19 *$ & $19 *$ & $15^{*}$ & $19^{*}$ & 29 & $40^{*}$ & $15^{*}$ \\
\hline & $\mathrm{P} 10$ & 66 & 32 & 23 & $21^{*}$ & 21 & 21 & 60 & $49 *$ & 45 & 36 \\
\hline & P11 & $19 *$ & $19 *$ & $22 *$ & $22 *$ & 22 & $16^{*}$ & 16 & $14 *$ & $15^{*}$ & $15^{*}$ \\
\hline & P12 & 30 & $30 *$ & $25 *$ & $20 *$ & $18^{*}$ & 17 & $13^{*}$ & $10 *$ & 30 & 30 ** \\
\hline & Average bid & 39.9 & 32.8 & 27.3 & 25.2 & 27.1 & 20.5 & 27.2 & 29.8 & 32.2 & 34.7 \\
\hline & Av. winner & 21.3 & 27.0 & 25.3 & 21.5 & 18.9 & 17.6 & 16.0 & 21.8 & 21.0 & 21.8 \\
\hline
\end{tabular}

Table 2/0

\begin{tabular}{|c|c|c|c|c|c|c|c|c|c|c|c|}
\hline \multicolumn{12}{|c|}{ Stage \# } \\
\hline \multirow{15}{*}{$\begin{array}{l}\mathrm{P} \\
\mathrm{L} \\
\mathrm{A} \\
\mathrm{Y} \\
\mathrm{E} \\
\mathrm{R}\end{array}$} & & 1 & 2 & 3 & 4 & 5 & 6 & 7 & 8 & 9 & 10 \\
\hline & P1 & $35^{*}$ & 67 & $37^{*}$ & 48 & 99 & 80 & 80 & $31 *$ & 37 & 100 \\
\hline & $\mathrm{P} 2$ & $31 *$ & 37 & $28 *$ & 30 & 31 & $25^{*}$ & 27 & $25^{*}$ & 65 & $40^{*}$ \\
\hline & P3 & $38 *$ & 42 & 35 & $30 *$ & 31 & $39 *$ & $39 *$ & $39 *$ & 39 & 35 \\
\hline & P4 & 67 & $43^{*}$ & 32 & 32 & $25^{*}$ & 30 & $25^{*}$ & $28^{*}$ & $30 *$ & 80 \\
\hline & P5 & 37 & $25^{*}$ & $30 *$ & $30 *$ & 25 & $25^{*}$ & $25^{*}$ & $25 * *$ & $25^{*}$ & 25 \\
\hline & P6 & 45 & 45 & 42 & $29 *$ & 80 & 89 & 74 & 79 & 35 & 71 \\
\hline & P7 & $50 * *$ & $35^{*}$ & 35 & $20 *$ & $20 *$ & $20 *$ & $20^{*}$ & 30 & $20 *$ & $20 *$ \\
\hline & P8 & $7 *$ & 41 & $31 *$ & 27 & $20^{*}$ & 26 & 32 & 100 & $23^{*}$ & $24 *$ \\
\hline & P9 & $50 *$ & $31^{*}$ & $30 *$ & 30 & 30 & 35 & 24 & $21 * *$ & $21 *$ & $35^{*}$ \\
\hline & P10 & $50 * *$ & 47 & 40 & 35 & $30 *$ & $30 * *$ & 30 & $25^{* *}$ & $25^{*}$ & $30^{*}$ \\
\hline & P11 & 69 & $43^{*}$ & $29 *$ & $19 *$ & $26^{*}$ & $18^{*}$ & $22 *$ & $21 * *$ & $30 *$ & 25 \\
\hline & P12 & 60 & $25^{*}$ & 45 & $15^{*}$ & $10^{*}$ & $30 * *$ & $10^{*}$ & 43 & 35 & $28 *$ \\
\hline & Average bid & 44.9 & 40.1 & 34.5 & 28.8 & 35.6 & 37.3 & 34 & 38.1 & 32.1 & 42.8 \\
\hline & Av. winner & 37.3 & 33.7 & 30.8 & 23.8 & 21.8 & 26.7 & 23.5 & 26.9 & 24.9 & 29.5 \\
\hline
\end{tabular}


Table 3/0

\begin{tabular}{|c|c|c|c|c|c|c|c|c|c|c|c|}
\hline \multicolumn{12}{|c|}{ Stage \# } \\
\hline \multirow{15}{*}{$\begin{array}{l}\mathrm{P} \\
\mathrm{L} \\
\mathrm{A} \\
\mathrm{Y} \\
\mathrm{E} \\
\mathrm{R}\end{array}$} & & 1 & 2 & 3 & 4 & 5 & 6 & 7 & 8 & 9 & 10 \\
\hline & P1 & $27 *$ & 27 & $20 *$ & $19 *$ & $18 *$ & 18 & 9 & $7 *$ & $7 *$ & $5^{*}$ \\
\hline & $\mathrm{P} 2$ & 50 & $40 *$ & 30 & 25 & $20 *$ & 15 & 15 & 9* & $10 *$ & $8^{*}$ \\
\hline & P3 & $15^{*}$ & 23 & 19 & 20 & 15 & $14 *$ & 13 & 9* & $8 *$ & $6 *$ \\
\hline & $\mathrm{P} 4$ & $5 *$ & $11 *$ & $21 *$ & $17 *$ & $11^{*}$ & 9* & 17 & 9* & $17 *$ & $16^{*}$ \\
\hline & P5 & $9 *$ & $30 *$ & 32 & 21 & $15 *$ & $9 *$ & $10 *$ & 11 & 10 & 10 \\
\hline & P6 & 80 & 49 & 29 & $19 *$ & $19 *$ & $19 *$ & $8 *$ & 19 & 8 & $4 *$ \\
\hline & P7 & 42 & $20 *$ & 30 & $15 *$ & $15^{*}$ & $12 *$ & $12 *$ & 12 & $8^{*}$ & 9 \\
\hline & P8 & 45 & $21 *$ & $18 *$ & 27 & 20 & 19 & 15 & $10 *$ & 15 & 10 \\
\hline & P9 & $10 *$ & 20 & $15 *$ & $10 *$ & $20 *$ & 20 & $10 *$ & 10 & $5 *$ & 10 \\
\hline & $\mathrm{P} 10$ & 30 & $15 *$ & $20 *$ & 20 & $18 *$ & 18 & $10 *$ & $10 *$ & 10 & 8 \\
\hline & P11 & $30 *$ & $10 *$ & 20 & 21 & 17 & 13 & $11^{*}$ & 11 & $11 *$ & $11 *$ \\
\hline & P12 & 59 & 23 & $11 *$ & $8 *$ & $10 *$ & $12 *$ & 10 & $10 *$ & 100 & 100 \\
\hline & Average bid & 33.5 & 24.1 & 22.1 & 18.5 & 16.5 & 14.1 & 11.7 & 10.6 & 17.4 & 16.4 \\
\hline & Av. winner & 16 & 21 & 17.5 & 14.7 & 16.2 & 12.5 & 10.2 & 9.1 & 9.4 & 8.3 \\
\hline
\end{tabular}

\section{Table 4/0}

\begin{tabular}{|c|c|c|c|c|c|c|c|c|c|c|c|}
\hline \multicolumn{12}{|c|}{ Stage \# } \\
\hline \multirow{15}{*}{$\begin{array}{l}\mathrm{P} \\
\mathrm{L} \\
\mathrm{A} \\
\mathrm{Y} \\
\mathrm{E} \\
\mathrm{R}\end{array}$} & & 1 & 2 & 3 & 4 & 5 & 6 & 7 & 8 & 9 & 10 \\
\hline & $\mathrm{P} 1$ & $35^{*}$ & 45 & $24 *$ & $32 *$ & $23 *$ & $22 *$ & $22 * *$ & $13 *$ & $12 *$ & $9 *$ \\
\hline & $\mathrm{P} 2$ & $5 *$ & $25 *$ & 50 & 40 & 35 & 30 & $20 *$ & $20 *$ & 20 & 20 \\
\hline & P3 & 56 & $25 *$ & 37 & $13 *$ & $24 *$ & $26 *$ & $23 *$ & $20 *$ & $18 *$ & $15 *$ \\
\hline & $\mathrm{P} 4$ & 50 & 49 & $39 *$ & 38 & 37 & 36 & 35 & $20 * *$ & $19 *$ & $18 *$ \\
\hline & P5 & 70 & $30^{*}$ & $30 *$ & $32 *$ & $31 *$ & 29 & 30 & $20 * *$ & 18 & $15^{*}$ \\
\hline & P6 & $49 *$ & $39 *$ & 36 & $20 *$ & $30 *$ & 35 & $19 *$ & 22 & $18 * *$ & 80 \\
\hline & P7 & 38 & $41 *$ & $36 *$ & 26 & 28 & $24 *$ & $22 * *$ & 24 & 24 & $30 *$ \\
\hline & P8 & $20 *$ & 69 & $34 *$ & 43 & 29 & $28 *$ & 28 & $20 *$ & 20 & 100 \\
\hline & P9 & $40 *$ & $51 *$ & 42 & $33^{*}$ & 37 & 30 & $25 *$ & 31 & 20 & 100 \\
\hline & P10 & 60 & 36 & $23 *$ & $35^{* *}$ & 40 & $20 *$ & 30 & $21 *$ & $19 *$ & $15 *$ \\
\hline & P11 & 37 & 48 & 38 & $35 * *$ & $30 *$ & 33 & $27 *$ & $24 *$ & $18 * *$ & 100 \\
\hline & P12 & $36^{*}$ & $43 *$ & $37 *$ & 32 & $29 *$ & $31 *$ & 30 & 26 & $16^{*}$ & 20 \\
\hline & Average bid & 41.3 & 41.8 & 35.5 & 31.6 & 31.1 & 28.7 & 25.9 & 21.8 & 18.5 & 43.5 \\
\hline & Av. winner & 30.8 & 36.3 & 31.9 & 28.6 & 27.8 & 25.2 & 22.6 & 19.8 & 17.1 & 17 \\
\hline
\end{tabular}


Table 5/0

\begin{tabular}{|c|c|c|c|c|c|c|c|c|c|c|c|}
\hline \multicolumn{12}{|c|}{ Stage \# } \\
\hline \multirow{15}{*}{$\begin{array}{l}\mathrm{P} \\
\mathrm{L} \\
\mathrm{A} \\
\mathrm{Y} \\
\mathrm{E} \\
\mathrm{R}\end{array}$} & & 1 & 2 & 3 & 4 & 5 & 6 & 7 & 8 & 9 & 10 \\
\hline & $\mathrm{P} 1$ & $10 *$ & $20 *$ & $20 *$ & $20 * *$ & $15^{*}$ & $15^{* *}$ & 15 & 20 & $12 *$ & $28 *$ \\
\hline & $\mathrm{P} 2$ & 23 & 32 & 22 & $17 * *$ & 25 & 25 & $32 *$ & 24 & 24 & $35 * *$ \\
\hline & P3 & 39 & $28 *$ & $22 *$ & 20 & 42 & 39 & 24 & 27 & 38 & 40 \\
\hline & $\mathrm{P} 4$ & $37 *$ & 33 & $23 *$ & $20 * *$ & $25^{*}$ & $25^{*}$ & 22 & 25 & 30 & $20 *$ \\
\hline & P5 & $30 *$ & 29 & 20 & $19 *$ & 19 & $14 *$ & $14 *$ & $14 *$ & $14 *$ & 30 \\
\hline & P6 & $13 *$ & $20 *$ & 27 & $15^{*}$ & 50 & $15^{*}$ & 25 & $13 *$ & $30 *$ & $30 *$ \\
\hline & P7 & $30 *$ & $10 *$ & 43 & 32 & $10 *$ & $15^{*}$ & $12 *$ & $20 *$ & 17 & $13 *$ \\
\hline & P8 & 80 & 25 & 25 & 30 & $35^{*}$ & 40 & 35 & $40 *$ & 40 & $35 * *$ \\
\hline & P9 & 40 & 35 & $15^{*}$ & $13 *$ & $15 *$ & $15^{* *}$ & $13 *$ & $15^{*}$ & $18^{*}$ & 15 \\
\hline & P10 & 33 & $13 *$ & $12 *$ & $11 *$ & 16 & 18 & $14 *$ & $17 *$ & $10 *$ & $26^{*}$ \\
\hline & P11 & 40 & 29 & 50 & 80 & 60 & 50 & 25 & 60 & 50 & 50 \\
\hline & P12 & $25^{*}$ & $25^{*}$ & $20 *$ & $17 * *$ & $19 *$ & $20 *$ & $15^{*}$ & 25 & $25^{*}$ & 30 \\
\hline & Average bid & 33.3 & 24.9 & 24.9 & 24.5 & 27.6 & 24.3 & 20.5 & 25 & 25.7 & 29.3 \\
\hline & Av. winner & 24.2 & 19.3 & 18.7 & 16.5 & 19.8 & 17 & 16.7 & 19.8 & 18.2 & 26.7 \\
\hline
\end{tabular}


Table 1/10

\begin{tabular}{|c|c|c|c|c|c|c|c|c|c|c|c|}
\hline \multicolumn{12}{|c|}{ Stage \# } \\
\hline \multirow{15}{*}{$\begin{array}{l}\mathrm{P} \\
\mathrm{L} \\
\mathrm{A} \\
\mathrm{Y} \\
\mathrm{E} \\
\mathrm{R}\end{array}$} & & 1 & 2 & 3 & 4 & 5 & 6 & 7 & 8 & 9 & 10 \\
\hline & P1 & $10^{*}$ & 24 & $19 *$ & 18 & 16 & 14 & $12 * *$ & $10 *$ & $10 * *$ & $10^{*}$ \\
\hline & $\mathrm{P} 2$ & $19^{*}$ & $15^{*}$ & $17 *$ & 18 & $17^{* * *}$ & $10^{* *}$ & $10 * *$ & 13 & $10 * *$ & $10^{* *}$ \\
\hline & P3 & $10^{*}$ & $50^{*}$ & 30 & $17 * *$ & $10^{* * *}$ & 20 & $10 *$ & 15 & $10 * *$ & 30 \\
\hline & $\mathrm{P} 4$ & 25 & $15^{*}$ & 20 & $17 *$ & $17^{* * *}$ & $12 *$ & 12 & $10 * *$ & $10 * *$ & 100 \\
\hline & P5 & 20 & 20 & $18^{*}$ & 18 & $11 *$ & $11 *$ & 11 & $10 * *$ & $10 * *$ & $10 * *$ \\
\hline & P6 & $20^{*}$ & 15 & 25 & 15 & $15^{*}$ & 13 & $12 * *$ & $10 * *$ & $10^{* * *}$ & $10 * *$ \\
\hline & P7 & 37 & $10^{*}$ & $13^{*}$ & $16^{*}$ & $10^{*}$ & $10^{* *}$ & $10 * *$ & $10 *$ & $10 * *$ & $10 * *$ \\
\hline & P8 & 59 & $19 *$ & 14 & $10^{*}$ & $12 *$ & $10^{* *}$ & $10 * *$ & $10 * *$ & 10 *** & $10 * *$ \\
\hline & P9 & $11^{*}$ & $11 *$ & $12 *$ & $12 *$ & 13 & $10 *$ & $10 * *$ & $10 * *$ & $10 * *$ & $10 * *$ \\
\hline & P10 & 87 & 87 & $18^{*}$ & $16^{*}$ & 16 & $10^{* *}$ & $10^{*}$ & $10 * *$ & $10^{* *}$ & $10^{*}$ \\
\hline & P11 & $30^{*}$ & 30 & 30 & 17 & 12 & $10 *$ & $10^{*}$ & $10 * *$ & $10 * *$ & $10 * *$ \\
\hline & P12 & 23 & 20 & 20 & $17 * *$ & 15 & 13 & 12 & $10 * *$ & $10 * *$ & $10 * *$ \\
\hline & Average bid & 29.3 & 26.3 & 19.7 & 15.9 & 13.7 & 11.9 & 10.9 & 10.7 & 10.0 & 19.2 \\
\hline & Av. winner & 16.7 & 20.0 & 16.2 & 15.0 & 13.1 & 10.4 & 10.4 & 10.0 & 10.0 & 10.0 \\
\hline
\end{tabular}

Table 2/10

\begin{tabular}{|c|c|c|c|c|c|c|c|c|c|c|c|}
\hline \multicolumn{12}{|c|}{ Stage \# } \\
\hline \multirow{15}{*}{$\begin{array}{l}\mathrm{P} \\
\mathrm{L} \\
\mathrm{A} \\
\mathrm{Y} \\
\mathrm{E} \\
\mathrm{R}\end{array}$} & & 1 & 2 & 3 & 4 & 5 & 6 & 7 & 8 & 9 & 10 \\
\hline & P1 & 45 & 45 & 25 & 20 & 29 & 17 & 14 & 20 & $10 * *$ & $10 * *$ \\
\hline & $\mathrm{P} 2$ & $10^{*}$ & $21 *$ & $37 *$ & $10^{*}$ & 17 & $10 * *$ & $10 * *$ & $10^{*}$ & 10 *** & $10 * *$ \\
\hline & P3 & 47 & 44 & $19^{*}$ & 34 & 90 & $15^{*}$ & 14 & $10^{* *}$ & $10^{* * *}$ & $10 * *$ \\
\hline & P4 & 60 & 30 & $10 * *$ & $10 * *$ & $10^{*}$ & $10 * *$ & $10 * *$ & $10 * *$ & 10 *** & $10 * *$ \\
\hline & $\mathrm{P} 5$ & $10^{*}$ & $20^{*}$ & 20 & $15^{*}$ & 18 & 17 & 15 & $10^{* * *}$ & $10^{* * *}$ & $10 * *$ \\
\hline & P6 & 55 & $10^{*}$ & $10^{*}$ & $10^{*}$ & $10^{*}$ & $10 * *$ & $10^{*}$ & $10^{*}$ & $10 * *$ & $10 * *$ \\
\hline & P7 & $25^{*}$ & 32 & 28 & $10 * *$ & 12 & $15^{*}$ & $10 *$ & $10^{* * *}$ & 10 *** & $10 * *$ \\
\hline & P8 & $30 *$ & $10^{*}$ & 10 ** & $10 *$ & $10^{*}$ & $10^{*}$ & $10 *$ & 10 ** & $10 *$ & $10 *$ \\
\hline & P9 & 40 & $10^{*}$ & $10^{*}$ & $20^{*}$ & $20 *$ & 30 & $10 * *$ & $10^{* * *}$ & $10 * *$ & $10 * *$ \\
\hline & P10 & $50^{*}$ & $10^{*}$ & 50 & 30 & $10^{*}$ & $10^{*}$ & $10^{* * *}$ & $10^{* *}$ & $10 * *$ & $10 *$ \\
\hline & P11 & 80 & 40 & $20^{*}$ & 20 & $17 *$ & 17 & $10 *$ & $10^{* * *}$ & $10 * *$ & 32 \\
\hline & P12 & $10^{*}$ & 45 & 70 & 35 & 27 & 10 ** & 40 & 50 & 20 & 15 \\
\hline & Average bid & 38.5 & 26.4 & 25.8 & 18.7 & 22.5 & 14.3 & 13.6 & 14.2 & 10.8 & 12.3 \\
\hline & Av. winner & 22.5 & 13.5 & 16.6 & 12.1 & 12.8 & 11.3 & 10.0 & 10.0 & 10.0 & 10.0 \\
\hline
\end{tabular}


Table 3/10

\begin{tabular}{|c|c|c|c|c|c|c|c|c|c|c|c|}
\hline \multicolumn{12}{|c|}{ Stage \# } \\
\hline \multirow{15}{*}{$\begin{array}{l}\mathrm{P} \\
\mathrm{L} \\
\mathrm{A} \\
\mathrm{Y} \\
\mathrm{E} \\
\mathrm{R}\end{array}$} & & 1 & 2 & 3 & 4 & 5 & 6 & 7 & 8 & 9 & 10 \\
\hline & P1 & $10^{*}$ & $15^{*}$ & $20^{*}$ & $25 * *$ & 24 & 15 & $10^{*}$ & 15 & $10 *$ & $10 * *$ \\
\hline & $\mathrm{P} 2$ & $28^{*}$ & $10^{*}$ & $20^{*}$ & $13 *$ & 23 & $10^{* * *}$ & 50 & $10 * *$ & 99 & 11 \\
\hline & P3 & $10^{*}$ & 50 & $10^{* *}$ & 80 & $12 *$ & $11 *$ & $12^{*}$ & 11 & $10 *$ & $10 * *$ \\
\hline & $\mathrm{P} 4$ & 35 & $25^{*}$ & 23 & 14 & $10^{*}$ & $12 *$ & $10 * *$ & $10^{*}$ & $10 * *$ & $10^{* * *}$ \\
\hline & P5 & 50 & $25^{*}$ & 25 & $15^{*}$ & 13 & $10^{* * *}$ & $10 * *$ & $10 * *$ & $10 * *$ & $10 * *$ \\
\hline & P6 & 50 & 30 & $10^{* * *}$ & 15 & $10^{*}$ & $10 *$ & $10^{* * *}$ & $10 * *$ & $10^{* * *}$ & $10 * *$ \\
\hline & P7 & $25^{*}$ & 25 & $20 *$ & $17^{*}$ & $12 * *$ & $10^{*}$ & $10 * *$ & $10 *$ & $10 * *$ & $10 * *$ \\
\hline & P8 & 50 & $24 *$ & 24 & $19^{*}$ & 14 & $10 * *$ & $10 * *$ & $10 * *$ & 10 *** & $10 * *$ \\
\hline & P9 & $85^{*}$ & 35 & $15^{*}$ & 18 & $14 *$ & 15 & $11 *$ & 11 & $10 * *$ & $10 * *$ \\
\hline & P10 & $50^{*}$ & $45^{*}$ & 38 & 17 & $12 * *$ & 25 & 25 & 25 & $10 * *$ & $10 * *$ \\
\hline & P11 & 99 & 99 & 35 & $25 * *$ & 27 & 17 & 12 & $10^{*}$ & $10^{*}$ & $10 * *$ \\
\hline & P12 & 40 & 20 & $14 *$ & $10^{*}$ & $10^{*}$ & 11 & $10 * *$ & $10 * *$ & $10 * *$ & $10 * *$ \\
\hline & Average bid & 44.3 & 33.6 & 21.2 & 22.3 & 15.1 & 13.0 & 15.0 & 11.8 & 17.4 & 10.1 \\
\hline & Av. winner & 34.7 & 24.0 & 15.6 & 17.7 & 11.4 & 10.4 & 10.3 & 10.0 & 10.0 & 10.0 \\
\hline
\end{tabular}

Table 4/10

\begin{tabular}{|c|c|c|c|c|c|c|c|c|c|c|c|}
\hline \multicolumn{12}{|c|}{ Stage \# } \\
\hline \multirow{15}{*}{$\begin{array}{l}\mathrm{P} \\
\mathrm{L} \\
\mathrm{A} \\
\mathrm{Y} \\
\mathrm{E} \\
\mathrm{R}\end{array}$} & & 1 & 2 & 3 & 4 & 5 & 6 & 7 & 8 & 9 & 10 \\
\hline & P1 & $30^{*}$ & $25^{*}$ & 40 & 28 & 20 ** & $17 *$ & $18 * *$ & 19 & $10^{*}$ & 25 \\
\hline & $\mathrm{P} 2$ & $10^{*}$ & $25^{*}$ & 29 & $25^{*}$ & 30 & $15^{*}$ & $11 *$ & 100 & $22 * *$ & $19^{*}$ \\
\hline & $\mathrm{P} 3$ & $20 *$ & $15^{*}$ & $20 *$ & $17 *$ & $17^{*}$ & 17 & $14 *$ & $12 *$ & 25 & $56^{*}$ \\
\hline & P4 & 49 & 39 & 30 & $20^{*}$ & 20 ** & $20 * *$ & $10 * *$ & $10^{*}$ & $10 * *$ & 20 \\
\hline & P5 & 40 & $40 * *$ & 35 & 25 & $20 *$ & 20 & 15 & 14 & $12 * *$ & $12 *$ \\
\hline & P6 & 55 & 35 & $25^{*}$ & $20^{*}$ & 20 & 20 & $10 * *$ & 15 & 55 & 55 \\
\hline & P7 & $40^{*}$ & 35 & $25^{*}$ & $20^{*}$ & 20 & $15^{*}$ & $14 *$ & $14 *$ & $14 *$ & 14 \\
\hline & P8 & $17 *$ & 27 & $20 * *$ & 25 & $19 *$ & $17^{*}$ & 30 & 17 & $10 * *$ & $10 *$ \\
\hline & P9 & 75 & $40 * *$ & $30 *$ & 30 & 30 & $20 * *$ & 20 & 20 & 15 & 99 \\
\hline & P10 & 60 & $14 *$ & $23 *$ & 27 & $18^{*}$ & $17 * *$ & 15 & $10 *$ & $12 * *$ & $12 *$ \\
\hline & P11 & $12^{*}$ & 52 & $28^{*}$ & $24 *$ & 32 & $17 * *$ & $18^{* * *}$ & $16^{*}$ & 15 & $13^{*}$ \\
\hline & P12 & 50 & $25^{*}$ & $20 * *$ & $25 * *$ & $19 *$ & 18 & 15 & $13^{*}$ & $13^{*}$ & 13 \\
\hline & Average bid & 38.2 & 31 & 27.1 & 23.8 & 22.1 & 17.8 & 15.8 & 21.7 & 17.8 & 29 \\
\hline & Av. winner & 21.5 & 26.3 & 23.9 & 21.6 & 19 & 17.3 & 13.8 & 12.9 & 12.9 & 20.3 \\
\hline
\end{tabular}


Table 5/10

\begin{tabular}{|c|c|c|c|c|c|c|c|c|c|c|c|}
\hline \multicolumn{12}{|c|}{ Stage \# } \\
\hline \multirow{15}{*}{$\begin{array}{l}\mathrm{P} \\
\mathrm{L} \\
\mathrm{A} \\
\mathrm{Y} \\
\mathrm{E} \\
\mathrm{R}\end{array}$} & & 1 & 2 & 3 & 4 & 5 & 6 & 7 & 8 & 9 & 10 \\
\hline & $\mathrm{P} 1$ & $20 *$ & 19 & $15^{*}$ & 20 & $10 * *$ & 15 & $10 * *$ & 15 & 100 & $10 * *$ \\
\hline & $\mathrm{P} 2$ & 25 & $12 *$ & $15 *$ & 13 & $11 *$ & 11 & $10 * *$ & 19 & 19 & 11 \\
\hline & P3 & $19 *$ & 19 & 16 & $16^{*}$ & 15 & $10^{*}$ & $10 * *$ & $10^{*}$ & $10^{*}$ & $10 * *$ \\
\hline & $\mathrm{P} 4$ & $10 *$ & $10 *$ & $11 *$ & 15 & 25 & $10^{*}$ & $10 * *$ & $10 *$ & $10 *$ & $10 *$ \\
\hline & P5 & 23 & $15^{*}$ & $13 *$ & 12 & $10 *$ & $10 * *$ & $10 * *$ & $10 * *$ & $10 * *$ & $10 *$ \\
\hline & P6 & 47 & 30 & 14 & $10 *$ & $10 * *$ & $10 * *$ & $10 * *$ & $10 * *$ & $10 *$ & $10 *$ \\
\hline & P7 & $20 *$ & $10 *$ & $10 *$ & $10 *$ & $10 *$ & $10^{*}$ & $10 *$ & $10 *$ & $10 *$ & 20 \\
\hline & P8 & 25 & 20 & $10 *$ & $15^{*}$ & 15 & $10^{*}$ & $10 * *$ & $10 * *$ & $10 *$ & $10 * *$ \\
\hline & P9 & 12 & 12 & 20 & 16 & $10 * *$ & 12 & $10 * *$ & $12 * *$ & $10 * *$ & 12 \\
\hline & P10 & 40 & 40 & 23 & 25 & $10 * *$ & 20 & 20 & 20 & 15 & $10 * *$ \\
\hline & $\mathrm{P} 11$ & $10 *$ & $11 *$ & $12 *$ & $10 *$ & $10 * *$ & $10 *$ & $10 * *$ & $10 * *$ & $10 * *$ & $10 *$ \\
\hline & P12 & $10 *$ & $15 *$ & $11 *$ & $10 *$ & $10 * *$ & 12 & $12 * *$ & $10 * *$ & $10 * *$ & 50 \\
\hline & Average bid & 21.8 & 17.8 & 14.2 & 14.3 & 12.2 & 11.7 & 11 & 12.2 & 18.7 & 14.4 \\
\hline & Av. winner & 14.8 & 12.2 & 12.1 & 11.8 & 10.1 & 10 & 10.2 & 10.2 & 10 & 10 \\
\hline
\end{tabular}




\section{Appendix C: Instructions}

The following game will be played for 10 rounds. In each round your reward will depend on your choice, as well as the choice made by one other person in this room. However, in each round you will not know the identity of this person and you will not learn this subsequently.

At the beginning of round 1 , you are asked to choose a number between 0 and 100 $\{10$ and 100 in the floor treatment $\}$, and then to write your choice on card number 1 (please note that the 10 cards you have are numbered $1,2, \ldots, 10$ ). Please write also your registration number on this card. Then we will collect all the cards of round 1 from the students in the room and put them in a box.

The monitor will then randomly take two cards out of the box. The numbers on the two cards will be compared. If one student chose a lower number than the other student, then the student that chose the lowest number will win points equal to the number he/she chose. The other student will get no points for this round. If the two cards have the same number, then each student gets points equal to half the number chosen. The monitor will then announce (on a blackboard) the registration number of each student in the pair that was matched, and indicate which of these students chose the lower number and what his/her number was.

Then the monitor will take out of the box another two cards without looking, compare them, reward the students, and make an announcement, all as described above. This procedure will be repeated for all the cards in the box. That will end round 1, and then round 2 will begin. The same procedure will be used for all 10 rounds. 
Appendix D: Figures

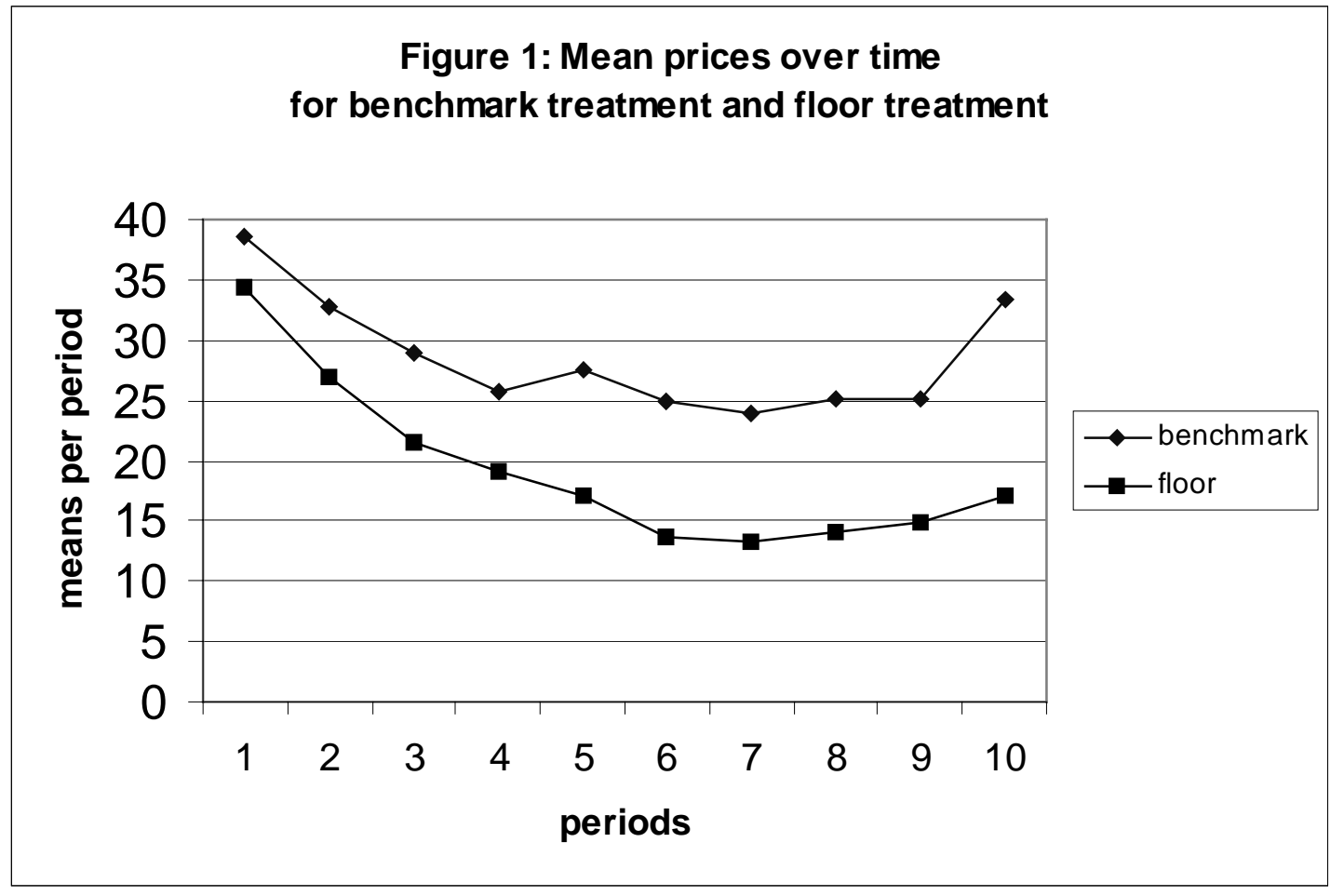

Figure 2: Relative frequencies of prices for last five periods in benchmark and floor treatment

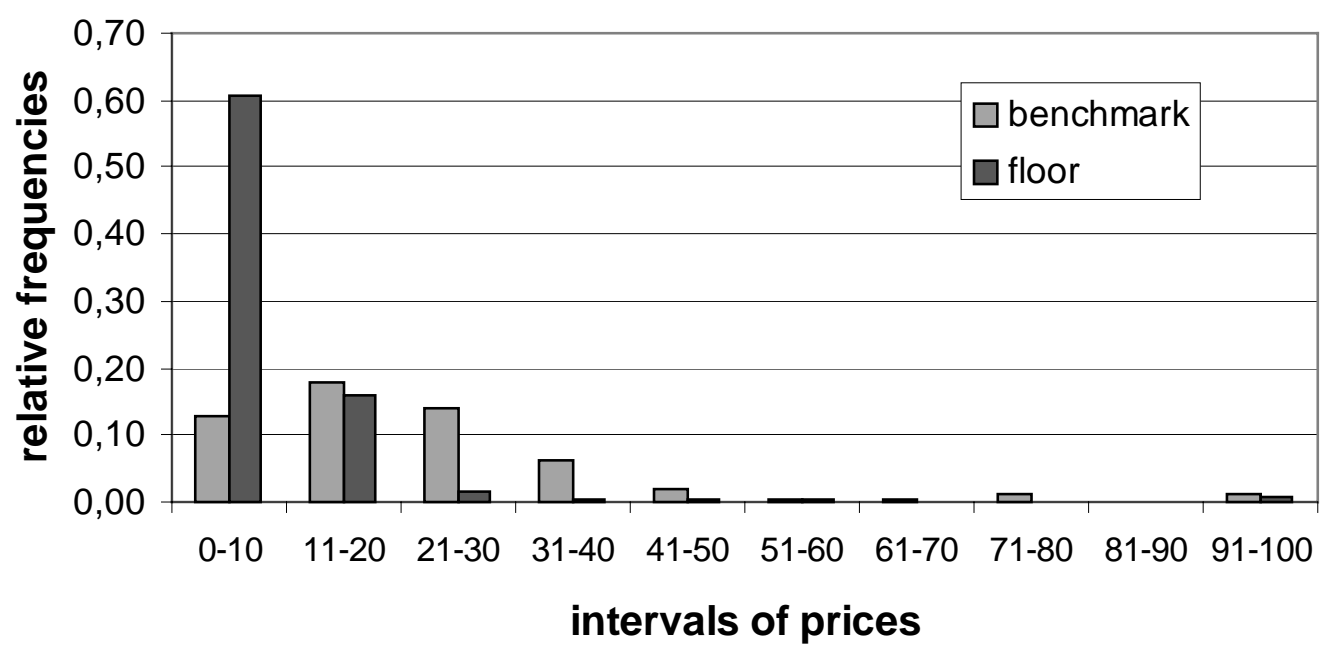


Figure 3:

Logit Equilibrium Frequencies for

Benchmark and Floor Treatment

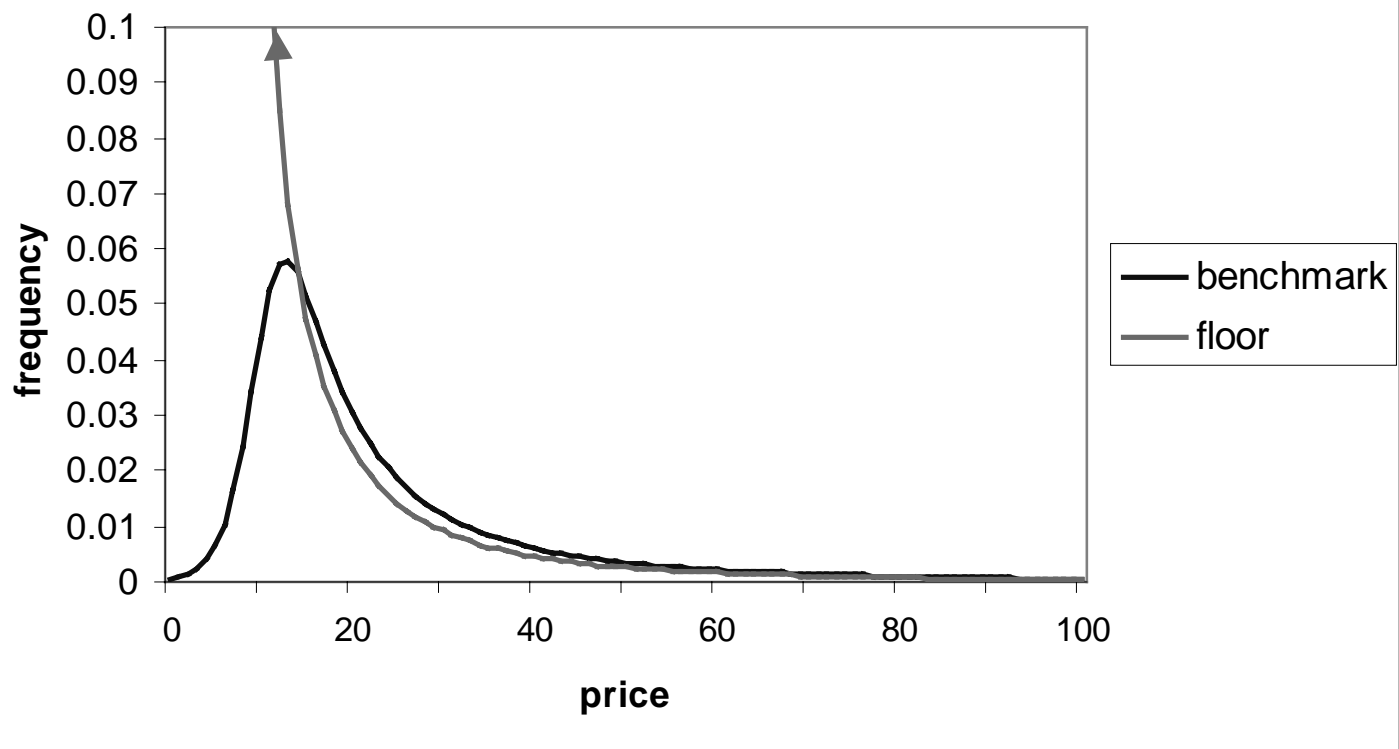

